\title{
A low-cost, low-density and corrosion resistant compositionally complex alloy: AIFeMnSi
}

\author{
S.P. O’Brien ${ }^{\mathrm{a}}$, L. Esteves ${ }^{\mathrm{a}}$, N. Birbilis ${ }^{\mathrm{b}}$, and R.K. Gupta ${ }^{\mathrm{a}}$ \\ ${ }^{a}$ Department of Chemical, Biomolecular and Corrosion Engineering, The \\ University of Akron, Akron, Ohio, 44325, USA. \\ ${ }^{\mathrm{b}}$ College of Engineering \& Computer Science, The Australian National University, \\ Acton, ACT, 2601, Australia \\ Corresponding author: R.K. Gupta, email: rgupta@uakron.edu

\begin{abstract}
A new class of compositionally complex alloy, consisting of equiatomic concentrations of $\mathrm{Al}, \mathrm{Fe}$, $\mathrm{Mn}$ and $\mathrm{Si}$ is reported. The alloy was characterized using scanning electron microscopy and energy-dispersive X-ray spectroscopy. Corrosion behavior of the AlFeMnSi alloy, as evaluated using potentiodynamic polarization tests and electrochemical impedance spectroscopy in $0.6 \mathrm{M}$ $\mathrm{NaCl}$ solution, was comparable with that of stainless steel (SS) 304L. X-ray photoelectron spectroscopy was used to study the AlFeMnSi surface film. The AlFeMnSi alloy also exhibited a lower cost, lower density, and a higher hardness as compared with SS 304L, rendering it a promising alloy for bespoke applications.
\end{abstract}

Keywords: Compositionally complex alloy, High entropy alloy, Corrosion, Passivation 
The development of new metallic materials exhibiting high corrosion resistance at lower cost is necessary to meet the demand for materials for advanced technologies. It is also beneficial if such materials can result from the utilization of recycled commodity metals. Typical corrosion resistant alloys, such as stainless steels (SS) and nickel based alloys, rely on their ability to form and maintain a thermodynamically stable passive film for corrosion resistance [1]. Therefore, corrosion resistant alloys are nominally comprised of a high concentration of elements that provide corrosion resistance (such as chromium) which limits the selection of alloy compositions for corrosion resistance, but also dictates alloy cost and properties. For example, corrosion resistance of stainless steel depends upon the chromium and molybdenum content; whereby chromium facilitates the formation of Cr-rich passive film [1], and molybdenum helps in maintaining promoting repassivation [1,2], whilst additional alloying elements such as nickel are also often employed.

Development of the corrosion resistant alloys with properties beyond conventional limits has to date been hindered by a hitherto limited understanding of the structure / processing / property / performance relationship at various length scales, along with a lack of manufacturing technologies to engineer desired microstructures; whilst exploration of a finite compositional space was traditionally confined to alloys that could be readily cast. Recent research into so-called high entropy alloys, or more generally, compositionally complex alloys (CCAs) has revealed both a broad and previously unexplored compositional space in the context of metallic alloys. CCAs, comprised of four or more principal elements in near equiatomic ratios, are emerging alloys [3-4]. Many CCAs, depending upon composition, have been reported to possess unique properties that include super plasticity [5], high fracture toughness [6], high strength, and high resistance to environmental degradation in aqueous and high temperature environments [7]. Most corrosion resistant CCAs reported to date contain a high concentration of chromium, and therefore the mechanism for corrosion resistance has been proposed to be similar to that reported for $\mathrm{Fe}-\mathrm{Cr}$ and Ni-Cr based alloys [8]. A conventional Pitting Resistance Equivalent Number (PREN) type of approach for designing corrosion resistant CCAs has been proposed by several researchers [9]. This conventional approach, however, would result in CCAs with high cost and high density, and inhibit exploitation of the full potential of CCAs - which have been noted as being inherently corrosion resistant (in spite of complex compositions and heterogeneous microstructures) $[8,10]$. 
A comprehensive consideration regarding the properties typical of CCAs, along with the characteristics desired in corrosion resistant alloys (CRAs) may facilitate developing new concepts regarding the targeted development of CCAs with corrosion resistance as the goal. The alloyenvironment interface is a complex and dynamic system during corrosion, and a complete understanding of the interfaces between the environment (electrolyte), the surface film and the underlying metal interfaces, is still an area of active research. Subtle changes in a surface film and underlying alloy are known to strongly influence corrosion resistance. For example, the high pitting resistance of high-energy ball milled and sputter deposited Al-alloys has been attributed to the doping of $\mathrm{Al}_{2} \mathrm{O}_{3}$ surface films, by alloying elements [11].

Most recently, Qiu and co-workers have reported a new four-component CCA, AlTiVCr, which showed corrosion resistance superior to SS 304L [12-14], and indeed characteristics typical of highly corrosion resistant alloys. Surface analysis, using X-ray photoelectron spectroscopy (XPS), indicated the surface film was enriched in Al, owing to incongruent dissolution of the AlTiVCr alloy. In addition, the surface film was also comprised of a mixture of oxidized forms of the alloying elements (in proportions different to the bulk alloy composition) along with unoxidized metal $\left(\mathrm{M}^{0}\right)$. Such work has revealed the possibility of developing new CCAs where the surface film may not be composed of well-known passivating elements such as Cr. Moreover, given that CCA compositions are complex and unique, the possibility of forming a complex film containing several elements is possible. Therefore, studying the formation of the surface film on CCAs and exploring their corrosion resistance warrants focused study. In this work, a corrosion resistant CCA was produced, based on four principle elements: Al, Fe, Mn, Si. Surface analysis using X-ray photoelectron spectroscopy revealed the presence of an Al and Si rich surface film.

The AlFeMnSi alloy studied herein was synthesized by the arc melting process. Metal pieces (with a purity greater than or equal to $99.9 \%$ ) were placed in a copper crucible in equimolar proportions, and arc melted in an inert argon environment. The synthesized alloy specimen were flipped at least thrice, and re-melted multiple times in order to obtain a homogenous composition.

Scanning electron microscopy (SEM) was performed using a Tescan Lyra 3 FIB-FESEM utilizing a $20 \mathrm{kV}$ accelerating voltage. Secondary electron (SE) and backscattered electron (BSE) modes were used to characterize the alloy microstructure. Energy dispersive X-ray spectroscopy (EDSX) area mapping and point analysis were conducted to estimate the elemental distribution 
and approximate composition of phases. SEM and EDXS analysis were performed on six individual specimens to verify the repeatability of the alloy production process and to ensure reproducibility. Specimens for SEM and EDXS analysis were metallographically prepared to a $0.05 \mu \mathrm{m}$ surface finish using a colloidal silica suspension, and ultrasonically cleaned in ethanol.

A Wilson Tukon 1202 Vickers hardness tester was used to measure Vickers hardness. Specimens were prepared by grinding to a 1200 grit $\mathrm{SiC}$ paper surface finish, and then a load of 50 grams was applied with a dwell time of 10 seconds, for multiple measurements $(>10)$, in order to obtain average hardness values for each phase present in the alloy.

Potentiodynamic polarization (PDP) testing was utilized to electrochemically investigate the corrosion behavior and was performed on the six different specimens of same alloy composition. Specimens for corrosion testing were ground to a 1200 grit $\mathrm{SiC}$ paper surface finish. A conventional three-electrode electrochemical flat cell was utilized, employing a saturated calomel reference electrode and platinum mesh counter electrode. All tests were conducted in naturally aerated $0.6 \mathrm{M} \mathrm{NaCl}$ solution with a VMP300 potentiostat (Biologic). The open-circuit potential (OCP) was stabilized for an hour, followed by potentiodynamic polarization with a potential sweep rate of $0.167 \mathrm{mV} / \mathrm{s}$.

Electrochemical impedance spectroscopy (EIS) was conducted in $0.6 \mathrm{M} \mathrm{NaCl}$ solution. The OCP was stabilized for an hour, followed by measurements employing an alternating current frequency ranging from $100 \mathrm{kHz}$ to $10 \mathrm{mHz}$ with a voltage amplitude of $10 \mathrm{mV}$. All measurements were carried out with a Gamry Reference 600 potentiostat and all spectra were fitted with Z-View software.

Immersion tests were carried out in $0.6 \mathrm{M} \mathrm{NaCl}$ solution for two weeks. Specimens for immersion testing were metallographically prepared to a $0.05 \mu \mathrm{m}$ surface finish using a colloidal silica suspension, ultrasonically cleaned in ethanol, and rinsed with de-ionized water. After immersion, specimens were thoroughly rinsed with de-ionized water to remove $\mathrm{NaCl}$, and SEM imaging using a $5 \mathrm{kV}$ accelerating voltage was utilized to characterize the extent of corrosion damage.

X-ray photoelectron spectroscopy (XPS) was performed using a PHI VersaProbe 5000 XPS Microprobe to study the surface of specimens after two hours of immersion in $0.6 \mathrm{M} \mathrm{NaCl}$ solution. Survey spectra were obtained with a band pass energy of $117.4 \mathrm{eV}$ and a scan area of 200 
$\mu \mathrm{m}$, while higher resolution regional spectra were obtained with a band pass energy of $58.7 \mathrm{eV}$ and a scan area of $100 \mu \mathrm{m}$.

The low magnification back-scattered electron (BSE) image, presented in Figure 1a, suggested the presence of three different phases which are shown clearly in the high magnification BSE image in Figure 1b. Visible pores, marked by arrows in Figure 1b, formed during arc melting. An EDXS area map showing the distribution of the four elements within the alloy is presented in Figure 1c. Elemental distribution in each phase, determined using the point analysis, is tabulated in Figure 1d. The composition values presented in Figure 1d are averages of more than 28 measurements for each phase. Most notably, phase I and II were relatively rich in Al while lean in Si compared to phase III, which was rich in Si and lean in Al.

(a)

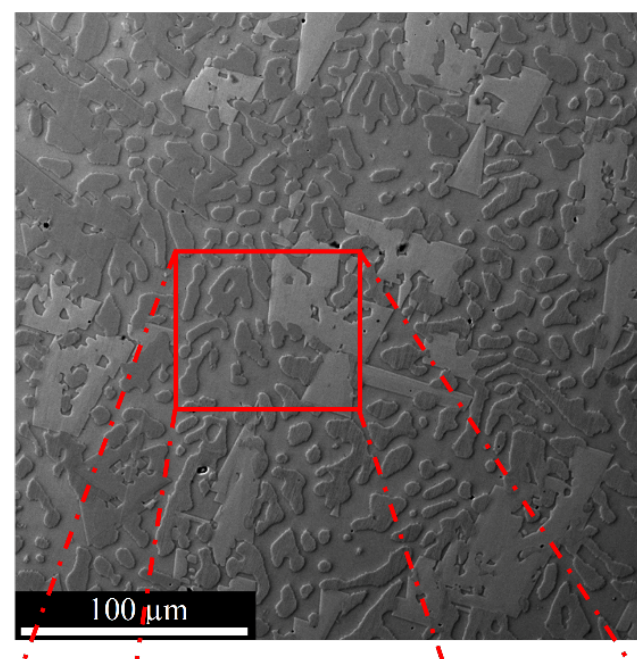

(c)

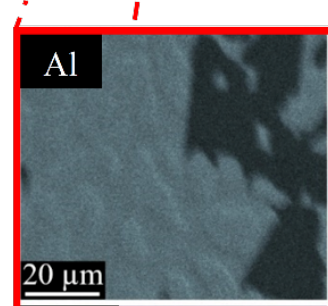

$\mathrm{Mn}$

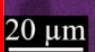

(b)

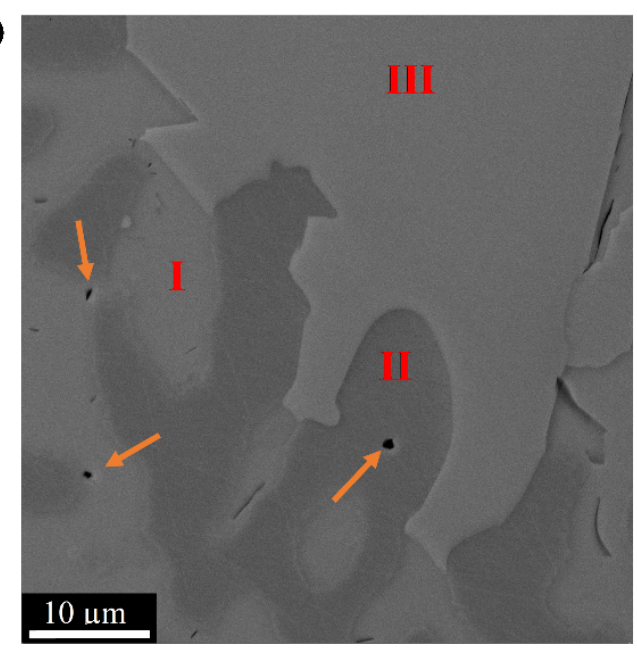

(d)

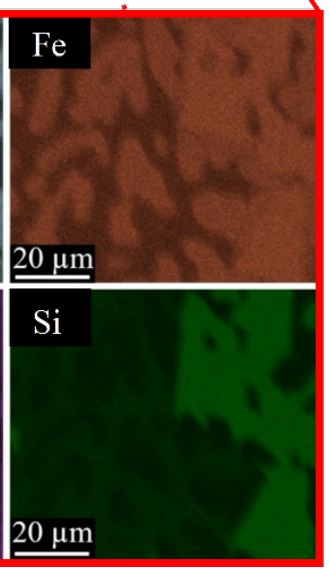

\begin{tabular}{|c|c|c|c|}
\hline Element & I (at. \%) & II (at. \%) & III (at. \%) \\
\hline $\mathrm{Al}$ & $20.30( \pm 0.72)$ & $20.80( \pm 1.05)$ & $9.79( \pm 0.81)$ \\
\hline $\mathrm{Fe}$ & $25.49( \pm 0.79)$ & $35.88( \pm 1.35)$ & $36.11( \pm 2.52)$ \\
\hline $\mathrm{Mn}$ & $39.11( \pm 1.27)$ & $30.31( \pm 0.82)$ & $27.39( \pm 2.11)$ \\
\hline $\mathrm{Si}$ & $15.05( \pm 0.71)$ & $12.97( \pm 1.28)$ & $26.40( \pm 1.28)$ \\
\hline
\end{tabular}

Fig. 1. (a) Backscattered electron image of as-cast AlFeMnSi, (b) high-magnification backscattered electron image, (c) EDXS map corresponding to a region in (a), and (d) composition (from EDXS point analysis) of phases in as-cast AlFeMnSi. 
Vickers hardness testing was performed on the individual phases: phases I, II, and III had the hardness of $1032( \pm 17), 952( \pm 13)$, and $1206( \pm 59) \mathrm{HV}$, respectively. The large standard deviation is attributed to the heterogeneous microstructure. The theoretical density of the AlFeMnSi CCA was $4.5 \mathrm{~g} / \mathrm{cm}^{3}$ [15], which is comparable with the density of Ti $\left(4.5 \mathrm{~g} / \mathrm{cm}^{3}\right)$ and significantly lower than that of austenitic stainless steel $304 \mathrm{~L}\left(8 \mathrm{~g} / \mathrm{cm}^{3}\right)$. The elemental cost of the alloy, determined using a 50 year average price of individual elements [16], was $1.18 \$ / \mathrm{kg}$ which is notably lower than commonly used corrosion resistant alloys such as SS 304L $(2.20 \$ / \mathrm{kg})$ or $316 \mathrm{~L}(3.28 \$ / \mathrm{kg})$.

Typical potentiodynamic polarization curves for $\mathrm{AlFeMnSi}$ (and SS 304L as a reference) in $0.6 \mathrm{M} \mathrm{NaCl}$ solution are presented in Figure 2a and electrochemical parameters derived from the PDP are presented in Table 1. The corrosion potential $\left(\mathrm{E}_{\text {corr }}\right)$ of the AlFeMnSi alloy was less noble than SS 304L, yet the breakdown potential $\left(\mathrm{E}_{\mathrm{b}}\right)$ of the two alloys were similar resulting in a larger passive window $\left(\mathrm{E}_{\mathrm{pw}}\right)$ for AlFeMnSi alloy. While AlFeMnSi alloy had a large deviation in the breakdown potential which was attributed to crevice corrosion. The corrosion current density $\left(i_{\text {corr }}\right)$ and overall passive current density for the two alloys were similar.

Nyquist and Bode plots for the AlFeMnSi alloy and the SS 304L in $0.6 \mathrm{M} \mathrm{NaCl}$ solution are shown in Figure $2 b$ and Figure $2 c$, respectively. The Bode plot (Figure $2 c$ ) exhibited a similar impedance $|\mathrm{Z}|$ vs. frequency response indicating a similar corrosion resistance between $\mathrm{AlFeMnSi}$ and SS 304L. EIS results were fitted using the electrical equivalent circuit (EEC) depicted in Figure $1 d$. The solution resistance (Rs) was estimated at a high frequency $(100 \mathrm{kHz}), \mathrm{R}_{\text {film }}$ and $\mathrm{CPE}_{\text {film }}$ represent the resistance and capacitance of the passive film, and $\mathrm{R}_{\mathrm{ct}}$ and $\mathrm{CPE}_{\mathrm{dl}}$ are the charge transfer resistance and double layer capacitance, respectively at low frequency. The constant phase elements (CPE) were used to describe the frequency dependence of the non-ideal capacitive behavior. When $\mathrm{n}$ equals 1 , a CPE simplifies to a capacitor; when $\mathrm{n}$ equals 0 , a CPE represents a pure resistor, and when $\mathrm{n}$ equals 0.5 , a CPE behaves as a Warburg impedance element. The simulated data show good coincidence with the experimental system, that is all fitting for the impedance data were performed using low $\chi^{2}$ values. The parameters extracted from the fitting are shown in Table 1. The polarization resistance $\mathrm{R}_{\mathrm{p}}$ (i.e., corrosion resistance) is theoretically equal to the sum of $R_{c t}$ and $R_{\text {film }}$ which are obtained from the fitting procedure. Accordingly, $S S 304 \mathrm{~L}$ exhibits slightly superior polarization resistance, but on the same order of magnitude as the AlFeMnSi alloy. 
(a)

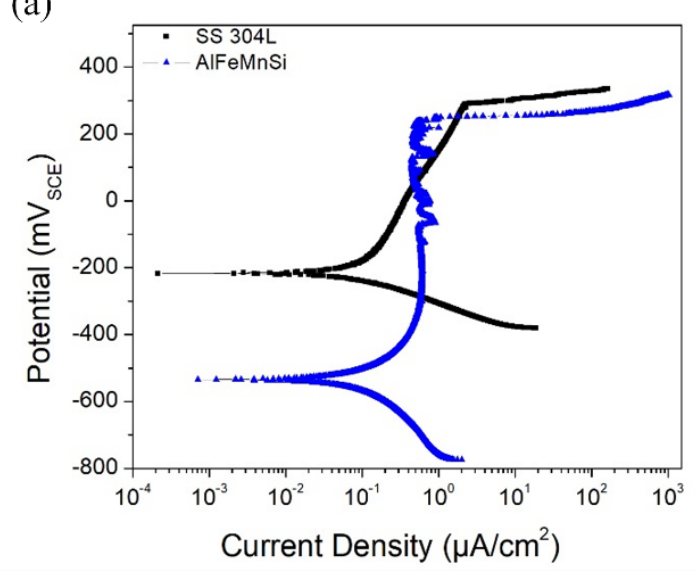

(c)

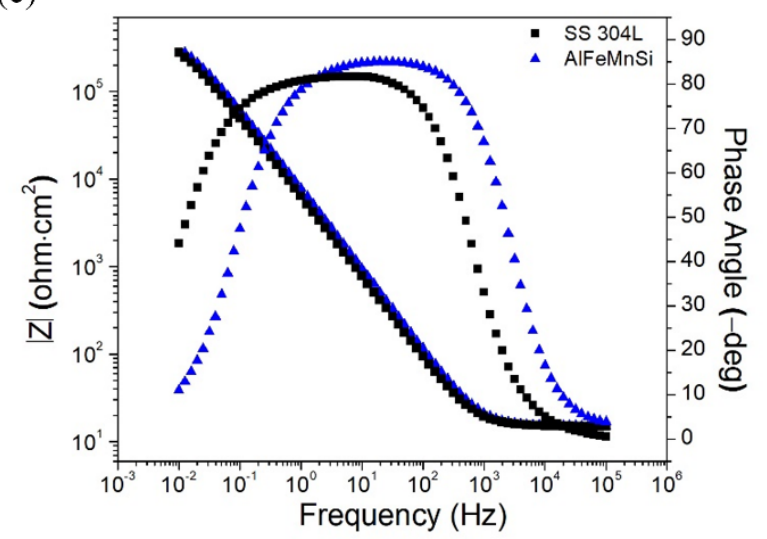

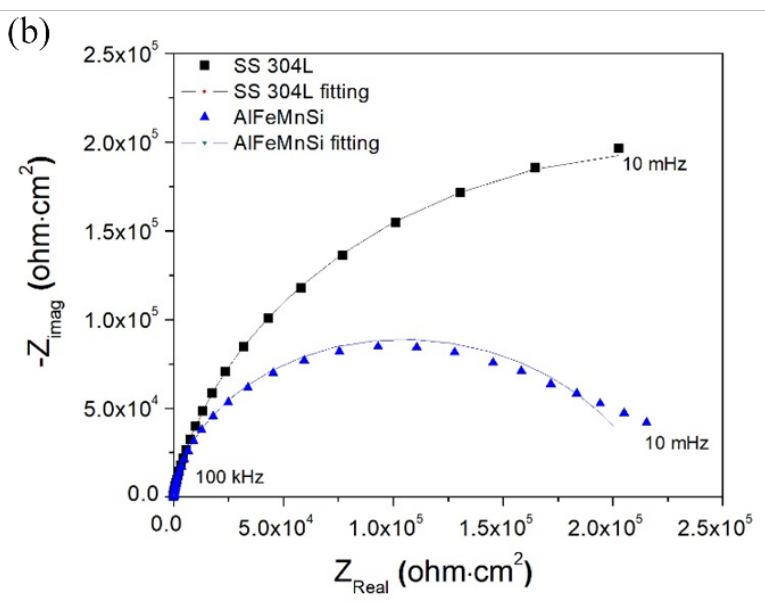

(d)

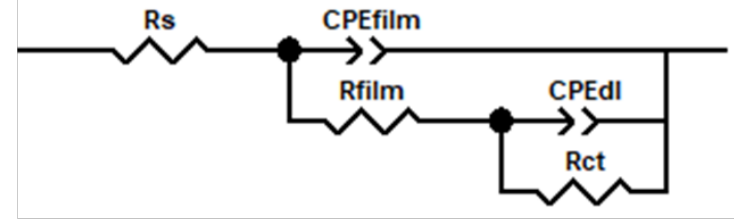

Fig. 2. (a) Potentiodynamic polarization curve collected using a potential sweep rate of 0.167 $\mathrm{mV} / \mathrm{s}$, (b) Nyquist diagram showing the comparison of the experimental data and the simulated data, (c) Bode plots for AlFeMnSi alloy and 304L SS in $0.6 \mathrm{M} \mathrm{NaCl}$ solution, and (d) the electrical equivalent circuit of the system.

Table 1. Electrochemical parameters for AlFeMnSi and SS 304L determined form the potentiodynamic polarization tests and EIS tests.

\begin{tabular}{|c|c|c|c|c|c|c|c|c|c|c|c|c|}
\hline Alloy & $\begin{array}{c}\mathrm{E}_{\text {corr }} \\
\left(\mathrm{mV}_{\mathrm{SCE}}\right)\end{array}$ & $\begin{array}{c}\mathrm{i}_{\text {corr }} \\
\left(\mu \mathrm{A} / \mathrm{cm}^{2}\right)\end{array}$ & $\begin{array}{c}\mathrm{E}_{\mathrm{b}} \\
\left(\mathrm{mV}_{\mathrm{SCE}}\right)\end{array}$ & $\begin{array}{c}\mathrm{E}_{\mathrm{pw}} \\
(\mathrm{mV})\end{array}$ & $\begin{array}{l}\mathrm{R}_{\mathrm{s}} \\
(\Omega)\end{array}$ & $\begin{array}{c}\mathrm{R}_{\mathrm{film}} \\
\left(\Omega . \mathrm{cm}^{2}\right)\end{array}$ & $\begin{array}{l}\mathrm{CPE}_{\text {film }} \\
\left(\mu \mathrm{Fs}^{\mathrm{n}-}\right. \\
\left.{ }^{1} \mathrm{~cm}^{2}\right)\end{array}$ & $\mathrm{n}$ & $\begin{array}{c}\mathrm{R}_{\mathrm{p}} \\
\left(\Omega \cdot \mathrm{cm}^{2}\right)\end{array}$ & $\begin{array}{l}\mathrm{CPE}_{\mathrm{dl}} \\
\left(\mu \mathrm{Fs}^{\mathrm{n}-}\right. \\
\left.{ }^{1} \cdot \mathrm{cm}^{2}\right)\end{array}$ & $\mathrm{n}$ & $X^{2}$ \\
\hline AlFeMnSi & $\begin{array}{l}-352 \\
( \pm 96)\end{array}$ & $0.2( \pm$ & $\begin{array}{c}112 \\
( \pm 130)\end{array}$ & $\begin{array}{c}464 \\
( \pm 172)\end{array}$ & 9 & $\begin{array}{c}3.90 \mathrm{x} \\
10^{4}\end{array}$ & 9.21 & 0.96 & $\begin{array}{c}1.49 \mathrm{x} \\
10^{5}\end{array}$ & 1.91 & $\begin{array}{c}0.5 \\
7\end{array}$ & $\begin{array}{l}3.4 \times \\
10^{-4}\end{array}$ \\
\hline SS 304L & -216 & 0.2 & 290 & 406 & 15 & $\begin{array}{c}4.49 \mathrm{x} \\
10^{4}\end{array}$ & 27.29 & 0.93 & $\begin{array}{c}4.26 \mathrm{x} \\
10^{5}\end{array}$ & 3.57 & $\begin{array}{c}0.6 \\
6 \\
\end{array}$ & $\begin{array}{l}7.7 x \\
10^{-5} \\
\end{array}$ \\
\hline
\end{tabular}

The SEM images after two weeks of immersion of the AlFeMnSi alloy and SS 304L in 0.6 $\mathrm{M} \mathrm{NaCl}$ solution, presented in Figure 3, showed localized corrosion in the AlFeMnSi alloy as well 
as in SS 304L. For the AlFeMnSi alloy, corrosion occurred in all three phases, with more damage visible in phases I and II, as highlighted in Figures 3a. Dark spots, pointed out by the orange arrows in Figure 3a, appear to be caused by the pores present in the alloy (Figure 1). Extensive localized and pitting corrosion on the surface of SS 304L was visible (Figure 3b). Comparing the two alloys, the amount of pitting corrosion on SS 304L may be more detrimental than the localized corrosion of the AlFeMnSi CCA.

(a)

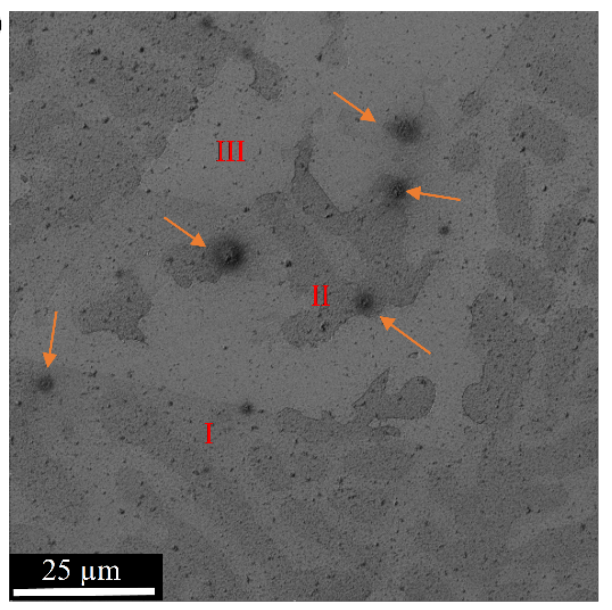

(b)

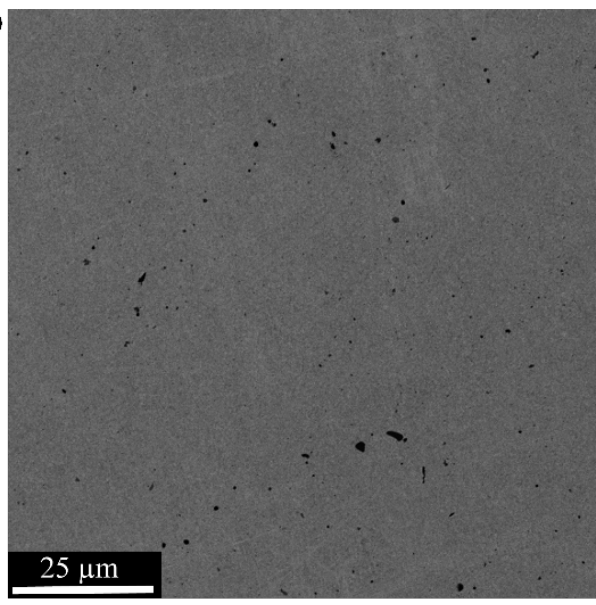

Fig. 3. Backscattered electron images of: (a) AlFeMnSi and (b) SS 304L following 2 weeks' immersion in $0.6 \mathrm{M} \mathrm{NaCl}$.

$\mathrm{X}$-ray photoelectron spectroscopy was performed to determine the chemical composition of the surface film developed after immersion of the AlFeMnSi alloy in $0.6 \mathrm{M} \mathrm{NaCl}$ solution. XPS survey and regional scans were conducted after regular intervals of sputtering to reveal the composition of the surface film along the depth, as seen in Figure 4a. The surface film, at sputtering time 0 , contained oxygen along with a majority of $\mathrm{Al}$ and $\mathrm{Si}$. After sputtering for 30 seconds, the oxygen content decreased significantly, and the atomic concentration of alloying elements increased. Such a decrease in oxygen content after 30 seconds of sputtering indicates a relatively thin surface film, as 30 seconds of sputtering time is equivalent to $3.25 \mathrm{~nm}$ of $\mathrm{SiO}_{2}$. Oxidation states of the elements were determined using regional scans and are presented in Figure 4b. The majority of the surface film, formed on a heterogenous microstructure, contained oxidized Al $\left(10.7 \% \mathrm{Al}^{\mathrm{x}}\right)$ and $\mathrm{Si}\left(9.7 \% \mathrm{Si}^{\mathrm{x}+}\right)$, while small amounts of oxidized $\mathrm{Fe}\left(1.4 \% \mathrm{Fe}^{\mathrm{x}}\right)$, oxidized $\mathrm{Mn}$ $\left(2.2 \% \mathrm{Mn}^{\mathrm{x}+}\right)$, and unoxidized elements $(2.3 \% \mathrm{Al}, 1.3 \% \mathrm{Fe}, 1.0 \% \mathrm{Mn}$ and $2.8 \% \mathrm{Si})$ were also 
detected. Content of oxidized elements decreased significantly just after 30 seconds of sputtering time which again indicates signals the presence of a thin surface film.
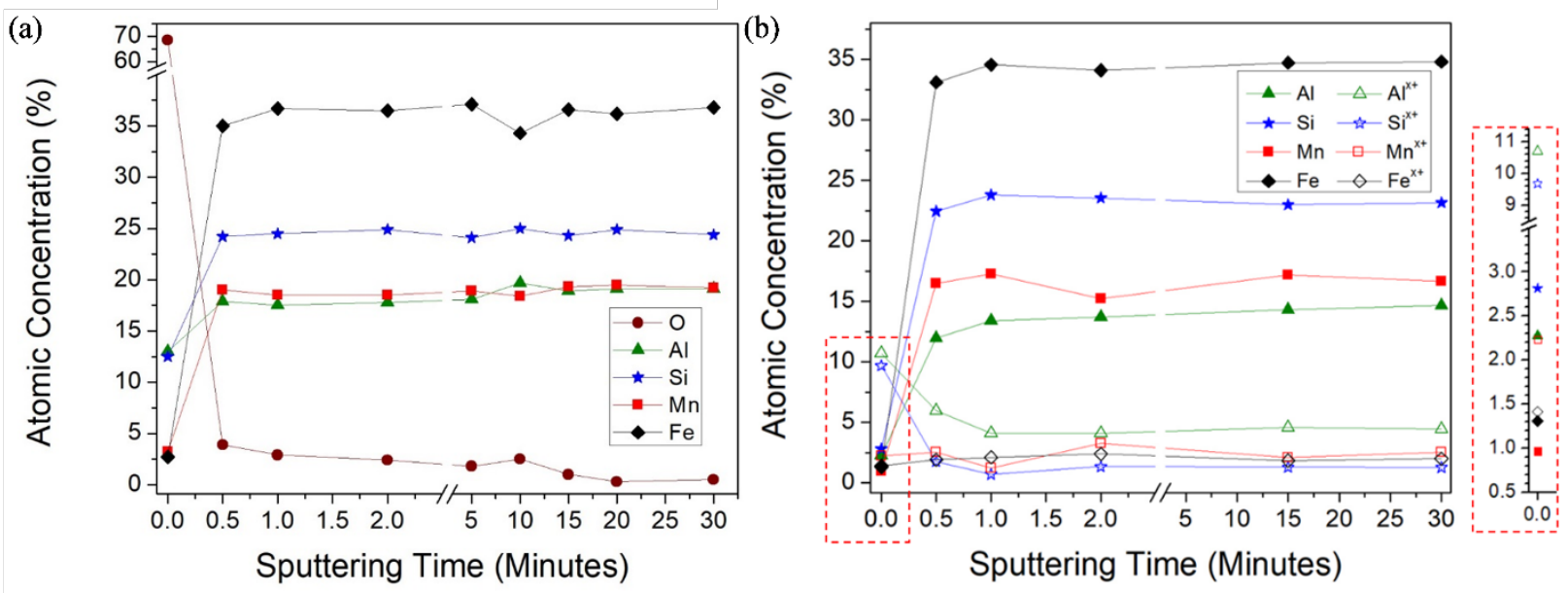

Fig. 4 (a) XPS atomic concentration of the oxygen and the elements in AlFeMnSi; and (b) oxidized (unfilled symbols) and unoxidized (filled symbols) species of AlFeMnSi alloy as a function of sputtering time following two hours of immersion in $0.6 \mathrm{M} \mathrm{NaCl}$. A zoomed in region is shown in the right.

The attainment of a high corrosion resistance in a multiphase CCA, comprised of low cost alloying elements, is not only unique - but sheds light on the notion that the means for attaining high corrosion resistance is not necessarily from thermodynamic stability (as may be interpreted from equilibrium calculations, such as in the development of Pourbaix diagrams). The high corrosion resistance of the AlFeMnSi alloy is attributed to the formation of a complex surface film enriched with $\mathrm{Al}$ and $\mathrm{Si}$. In addition, that surface film is likely to dynamically develop as a result of some finite alloy dissolution, evolving to provide a kinetic alloy stability. The high corrosion resistance of the multiphase alloy also indicate that homogenous microstructure is not a necessity rather characteristics of various phases dictate the overall corrosion performance. Further study is underway to develop insight into the structure of the surface film, especially on the individual phases. For further improvement of the properties of the alloy, the following are needed: choosing suitable homogenization heat treatments and optimizing the alloy composition.

A new multiphase compositionally complex alloy based on four principle commodity elements, AlFeMnSi, was successfully produced. The alloy contained three phases and exhibited 
excellent corrosion resistance, high hardness, and low-cost ( $\sim 6 \%$ less than stainless steel 304L)

and a low-density $\left(\sim 4.5 \mathrm{~g} / \mathrm{cm}^{3}\right)$. Analysis using XPS revealed formation of a complex $\mathrm{Al}$ and $\mathrm{Si}$ rich surface film, the stability of which was attributed to be responsible for the high corrosion resistance of the alloy. This work presented the possibility of obtaining high corrosion resistance from cheaper and lighter elements.

\section{Acknowledgement}

This project was supported by the Office of Naval Research under the contract ONR: N00014-171-2807 with Dr. Airan Perez as program officer. We thank Jonathan Geiser for assistance with hardness and PDP data collection.

\section{References}

[1] P. Marcus, "On some fundamental factors in the effect of alloying elements on passivation of alloys," Corros. Sci., vol. 36, no. 12, pp. 2155-2158, 1994.

[2] K. Sugimoto and Y. Sawada, "The role of alloyed molybdenum in austenitic stainless steels in the inhibition of pitting in neutral halide solutions," Corrosion, vol. 32, no. 9, pp. 347-352, 1976.

[3] Z. Wu, H. Bei, G. M. Pharr, and E. P. George, "Temperature dependence of the mechanical properties of equiatomic solid solution alloys with face-centered cubic crystal structures," Acta Mater., vol. 81, pp. 428-441, 2014.

[4] J. K. Jensen et al., "Characterization of the microstructure of the compositionally complex alloy Al 1 Mo 0.5 Nb 1 Ta 0.5 Ti 1 Zr 1,”Scr. Mater., vol. 121, pp. 1-4, 2016.

[5] A. V Kuznetsov, D. G. Shaisultanov, N. Stepanov, G. A. Salishchev, and O. N. Senkov, "Superplasticity of AlCoCrCuFeNi high entropy alloy," in Materials Science Forum, 2013, vol. 735, pp. 146-151.

[6] B. Gludovatz, A. Hohenwarter, D. Catoor, E. H. Chang, E. P. George, and R. O. Ritchie, "A fracture-resistant high-entropy alloy for cryogenic applications," Science (80-. )., vol. 345, no. 6201, pp. 1153-1158, 2014. 
[7] Y. Zhang et al., "Microstructures and properties of high-entropy alloys," Prog. Mater. Sci., vol. 61, pp. 1-93, 2014.

[8] Y. Qiu, S. Thomas, M. A. Gibson, H. L. Fraser, and N. Birbilis, "Corrosion of high entropy alloys," npj Mater. Degrad., vol. 1, no. 1, p. 15, 2017.

[9] P. Lu et al., "Computational design and initial corrosion assessment of a series of nonequimolar high entropy alloys,” Scr. Mater., vol. 172, pp. 12-16, 2019.

[10] Y. Qiu, M. A. Gibson, H. L. Fraser, and N. Birbilis, "Corrosion characteristics of high entropy alloys," Mater. Sci. Technol. (United Kingdom), vol. 31, no. 10, pp. 1235-1243, 2015.

[11] J. Esquivel, H. A. Murdoch, K. A. Darling, and R. K. Gupta, "Excellent corrosion resistance and hardness in Al alloys by extended solid solubility and nanocrystalline structure," Mater. Res. Lett., vol. 6, no. 1, pp. 79-83, 2018.

[12] Y. Qiu et al., "A lightweight single-phase AlTiVCr compositionally complex alloy," Acta Mater., vol. 123, pp. 115-124, 2017.

[13] Y. Qiu, S. Thomas, M. A. Gibson, H. L. Fraser, K. Pohl, and N. Birbilis, "Microstructure and corrosion properties of the low-density single-phase compositionally complex alloy AlTiVCr," Corros. Sci., vol. 133, pp. 386-396, 2018.

[14] Y. Qiu, S. Thomas, R. K. Gupta, T. Gengenbach, R. Jones, and N. Birbilis, “A Surface Study of the Native Oxide upon a Compositionally Complex Alloy," Corrosion, vol. 74, no. 12 , pp. 1312-1317, 2018.

[15] X. Huang, J. Miao, and A. A. Luo, "Lightweight AlCrTiV high-entropy alloys with dualphase microstructure via microalloying," J. Mater. Sci., vol. 54, no. 3, pp. 2271-2277, 2019.

[16] X. Fu, C. A. Schuh, and E. A. Olivetti, "Materials selection considerations for high entropy alloys," Scr. Mater., vol. 138, pp. 145-150, Sep. 2017. 